\title{
Impact of treatment delay in patients with bladder cancer managed with partial cystectomy in Quebec: a population-based study
}

\author{
Nader Fahmy, MD; Armen Aprikian, MD; Mohammed Al-Otaibi, MD; Simon Tanguay, MD; \\ Jordan Steinberg, MD; Suganthiny Jeyaganth, MSc; Moamen Amin, MD; Wassim Kassouf, MD
}

\section{Abstract}

Objective: Treatment delays have been associated with adverse outcomes in patients with bladder cancer treated with radical cystectomy (RC). We sought to evaluate the impact of treatment delay on disease recurrence and survival in patients with bladder cancer treated with partial cystectomy (PC) in Quebec.

Methods: We reviewed and obtained billing records for all patients who underwent PC and/or RC for bladder cancer in Quebec between 1983 and 2005. Analysis included age, sex, year of surgery, surgeon's age, hospital type, preoperative and postoperative visits with accompanying diagnoses and dates of death.

Results: A total of 714 patients underwent PC. The median patient age was 70 years. Two-hundred nineteen (30.7\%) patients experienced recurrence; of these, 52 (23.7\%) required salvage RC. Five-year overall and recurrence-free survival for patients who underwent PC were $49.8 \%$ and $40.3 \%$, respectively. Patients delayed more than 12 weeks from transurethral resection of bladder tumours (TURBT) to PC were at significantly increased risk of requiring salvage $\mathrm{RC}$ compared with those delayed 12 weeks or less (hazard ratio [HR] 3.0, $p<0.001$ ). Patients who underwent salvage RC had worse survival than patients who had upfront RC (HR 1.5, $p=0.006)$. Variables including age, sex, presence of hematuria, intravesical therapy, surgeon age, hospital PC volume, surgeon PC volume, type of hospital (academic v. nonacademic) or year of surgery were not significantly associated with PC treatment delay.

Conclusion: Treatment delay in patients with bladder cancer managed with PC was associated with increased risk of salvage RC. Patients with bladder cancer who underwent salvage RC had worse outcomes than those who had upfront cystectomy.

Can Urol Assoc J 2009;3(2):131-5

\section{Résumé}

Objectif : Chez les patients atteints de cancer de la vessie traités par cystectomie radicale (CR), un délai avant l'instauration du traitement est associé à des résultats défavorables. Nous avons tenté d'évaluer l'impact d'un tel délai sur la récidive de la maladie et le taux de survie des patients atteints de cancer de la vessie traités par cystectomie partielle (CP) au Québec.

Méthodologie : Les dossiers de facturation ont été obtenus pour les patients ayant subi une CP et/ou une CR pour le traitement d'un cancer de la vessie au Québec de 1983 à 2005. L'analyse tenait compte de l'âge, du sexe, de l'année de l'intervention chirurgicale, de l'âge du chirurgien, du type d'hôpital, des visites préopératoires et postopératoires, des comorbidités et des dates de décès.

Résultats : En tout, 714 patients dont l'âge moyen était de 70 ans ont subi une CP. De ce nombre, 219 patients (30,7 \%) ont présenté une récidive, dont 52 (23,7\%) nécessitant une CR de sauvetage. La survie globale après 5 ans et la survie sans récidive chez les patients ayant subi une CP étaient respectivement de 49,8\% et de 40,3\%. Un intervalle supérieur à 12 semaines entre la résection transurétrale de la tumeur et la CP a été associé à un taux accru de CR de sauvetage en comparaison avec un intervalle de 12 semaines ou moins (risque relatif [RR] 3,0, $p<0,001]$. La CR de sauvetage était associée à un taux inférieur de survie en comparaison avec les patients traités par CR dès le départ ( $R R$ 1,5, $p=0,006)$. Les autres variables, soit l'âge, le sexe, la présence d'une hématurie, le recours à une thérapie intravésicale, l'âge du chirurgien, le nombre de CP effectuées à I'hôpital, le nombre de CP effectuées par le chirurgien, le type d'hôpital (universitaire ou non universitaire), et l'année de l'intervention chirurgicale n'ont pas été associées de façon significative au délai avant la CP.

Conclusion : Le délai avant l'instauration du traitement chez les patients atteints de cancer de la vessie traités par CP a été associé à un taux accru de CR de sauvetage. Les patients atteints de cancer de la vessie qui ont subi une CR de sauvetage présentaient une issue de la maladie moins favorable que les patients traités par cystectomie dès le départ.

\section{Introduction}

In the United States, 67160 new cases of bladder cancer were expected to be diagnosed by the end of 2007; it was also estimated that 13750 patients would die from the disease. ${ }^{1}$ About $80 \%$ of patients presenting with muscleinvasive bladder cancer have no history of prior superficial disease. Furthermore, almost half of patients with invasive bladder cancer have already distant metastases at the time of presentation, which reflects the aggressive nature of this disease. ${ }^{2}$

Radical cystectomy (RC) with urinary diversion is the gold standard treatment for invasive bladder tumours. Few 
Fahmy et al.

studies have demonstrated that for a highly select patient population, a partial cystectomy (PC) may offer comparable cure rates to RC., ${ }^{3,4}$ Ideal candidates for PC are those with favourable disease characteristics such as small, solitary, primary tumours amenable to surgical resection with 2-cm margins, without the need for ureteral reimplantation. ${ }^{5,6}$

Even though treatment for invasive bladder cancer should be preferably initiated as soon as the diagnosis has been made, delays in providing such treatment can sometimes be unavoidable owing to factors related to the patient or health care system. We and others have shown that delaying RC is significantly associated with worse outcome. ${ }^{7-11}$ However, no studies have evaluated treatment delays among patients who underwent PC. The goal of the present study was to investigate variables associated with delays between transurethral resection of bladder tumours (TURBT) and PC and to examine the impact of such delays on disease outcome.

\section{Methods}

\section{Study population}

We obtained complete billing records for patients who underwent PC and/or RC for bladder cancer in the province of Quebec between 1983 and 2005 from the Quebec provincial database of physician fee for services claims (Régie de I'Assurance Maladie du Québec). Data received included the following information: sex and age of the patient, vital status and date of death of all patients, dates of relevant diagnostic and therapeutic procedures (TURBT, intravesical therapy, PC and RC), diagnostic codes given with each procedure using the International Classification of Diseases (ICD-9), anonymous unique identifier, age group of the urologist who provided the service and hospital name. We excluded patients aged younger than 18 years, those for whom there was no bladder tumour diagnostic code and those who did not have a TURBT before their PC. We measured treatment delay as the time from the date of most recent TURBT to the date of PC.

\section{Statistical analyses}

We expressed results as means and standard devi- ations (SDs). We first conducted both graphical (box plots) and statistical univariate analyses (Kruskall-Wallis test) to assess the relation between the delay variable and the following patient and provider characteristics: sex, age, presence of hematuria, hospital PC volume, surgeon PC volume, surgeon age groups, year, season and month of the tested procedure (TURBT or PC). Using Cox regression and a stepwise modelling approach, we identified variables with independent prognostic significance in relation to delay and we generated hazard ratios for each variable. We then examined the association between the delay variable and both the recurrence-free and the overall survival. We then generated Kaplan-Meier survival estimates. We defined recurrence-free survival as the need for either a TURBT or an RC after PC. Date of censoring was Dec. 31, 2003, to allow for at least 2 years of follow-up. We used the Cox proportional hazards models with shared frailty to assess the effect of preoperative delays on longterm survival. We used models with shared frailty to allow for within-group correlation (among patients treated by the same surgeon). We assessed the assumption of proportional hazards for each of the covariates by examining graphs of scaled Schoenfeld residuals and by using appropriate statistical tests. We estimated all models using Stata 9 (Stata Corp.).

\section{Results}

\section{Patient characteristics}

We included in our studuy 714 patients who underwent PC for bladder cancer performed by 153 surgeons in 82 hospitals between 1983 and 2005 in Quebec. The median patient age was 70 (mean 67.9 , SD 12.4) years. The male to female ratio was $2.6: 1$. A total of $219(30.7 \%)$ patients had local recurrence of the disease and required 1 or more interventions after their PC. Of the patients who had a recurrence, 167 (76.3\%) had a median of 1 TURBT (range 1-4) and $52(23.7 \%)$ required a salvage RC after their PC. The overall rate of salvage $\mathrm{RC}$ was $7.3 \%$. The median time to salvage $\mathrm{RC}$ was 17.6 months (range $9 \mathrm{~d}$ to $20.6 \mathrm{yr}$ ). The median follow-up period was 4.6 (mean 5.2) years. The 5 -year overall survival was $49.8 \%$ and recurrencefree survival was $40.3 \%$. 


\section{Diagnostic delay analyses}

Median diagnostic delays more than doubled in Quebec bewteen 1983 and 2005, going from 19 to 44 days, respectively, with a median overall delay of 28 days for the entire period of this study (Fig. 1). The mean overall delay was 54.9 (SD 8.8) days. Patients delayed more than 12 weeks from their TURBT to PC were at 3 times greater risk of requiring a salvage RC than those delayed 12 weeks or less (HR 3.0, 95\% confidence interval [Cl] $1.8-5.2, p=0.001$ ) (Fig. 2). Longer delays were associated with even greater risk of salvage RC (Table 1). The 10- and 30-week delays represented the 75th and 90th percentile, respectively. The 12-week delay cutoff was based on our previous study showing that patients with bladder tumours who experienced a delay longer than 12 weeks between their first family physician visits and RC in the province of Quebec were significantly more likely to experience worse outcomes. ${ }^{9}$ Patients who underwent salvage RC had worse survival than patients who had upfront RC for invasive bladder cancer, a patient population that we have previously reported on ${ }^{9}$ (HR 1.5, 95\% Cl 1.1-1.9, $p=0.006$ ) (Fig. 3). Interestingly, PC treatment delays did not significantly correlate with overall survival (HR 1.2 95\% Cl 1.0-1.5, $p=0.11$ ). Variables including patient age, sex, presence of hematuria, number of TURBTs before PC, intravesical therapy, surgeon age, hospital PC volume, surgeon PC volume, type of hospital (academic v. nonacademic) and year of surgery were not significantly associated with PC treatment delay.

\section{Discussion}

Our study showed that progressively increasing treatment delays among patients with bladder cancer managed with PC were associated with a progressively increasing risk of salvage RC. Patients who underwent salvage RC had significantly worse outcomes than those who had upfront cystectomy.

Radical cystectomy with urinary diversion is the method of choice for treating invasive bladder cancers. Studies have shown that, in carefully selected patients with small, solitary primary tumours at the dome or posterolateral wall of the bladder, PC can be a reasonable alternative to $\mathrm{RC}$ because PC allows radical excision of the tumour with comparably less morbidity and preservation of urinary and sexual functions. ${ }^{3-6}$ In our study, the local recurrence rate was $30.7 \%$, comparable with contemporary series reporting local recurrence rates of $19-35 \%{ }^{3,4}$

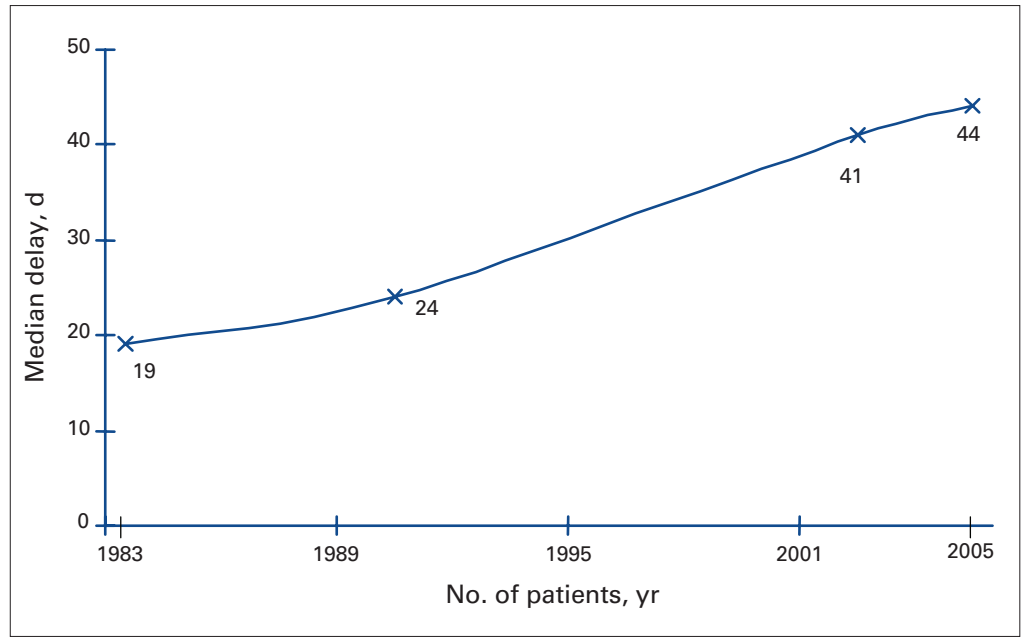

Fig. 1. Median delays among patients who underwent partial cystectomy between 1983 and 2005 .

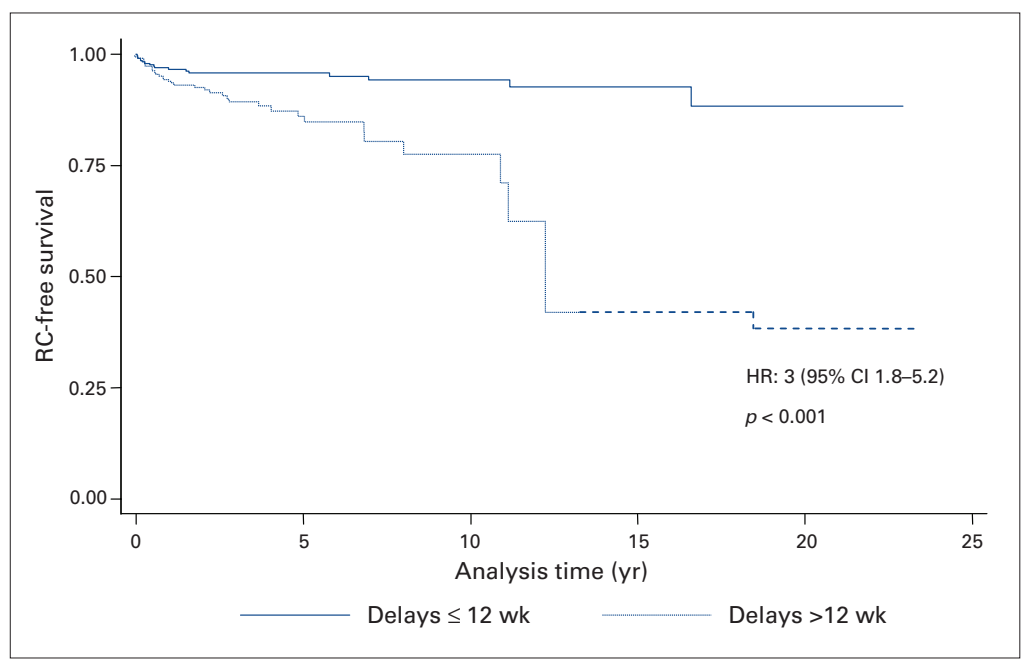

Fig. 2. Radical cystectomy (RC)-free survival estimates of patients who underwent partial cystectomy with delays longer than 12 weeks versus 12 weeks or less. $\mathrm{Cl}=$ confidence interval; $\mathrm{HR}=$ hazard ratio.

\begin{tabular}{l}
$\begin{array}{l}\text { Table 1. Partial cystectomy treatment delay and the } \\
\text { risk of requiring a salvage radical cystectomy }\end{array}$ \\
\begin{tabular}{lcr} 
Delays, wk & $\mathrm{HR}(95 \% \mathrm{Cl})$ & $p$ value \\
\hline 4 & $2.3(1.3-4.1)$ & 0.005 \\
$>10$ & $2.8(1.6-4.8)$ & $<0.001$ \\
$>12$ & $3.0(1.8-5.2)$ & $<0.001$ \\
$>30$ & $4.2(2.3-7.6)$ & $<0.001$ \\
$\mathrm{Cl}=$ confidence interval; $\mathrm{HR}=$ hazard ratio.
\end{tabular} \\
\hline
\end{tabular}


Fahmy et al.

Invasive bladder tumours are aggressive from the time of presentation, suggesting that delaying treatment for such cancer may lead to a worse outcome. Several patient and provider factors may play a role in delaying treatment among patients with bladder cancer; these include requests for a second opinion, medical clearance owing to Comorbid diseases, attempted less invasive procedures and patients' personal choices. ${ }^{10,11}$ Delays related to the health system include increased demand and/or inadequate resources. Interestingly, provinces that spent more on health care did not affect waiting lists for the procedure. ${ }^{12}$ Increased health care expenditure that was not related to physicians and/or pharmaceuticals correlated with longer delays. ${ }^{13}$

Several manuscripts have shown that delays of more than 12 weeks bewteen TURBT and RC significantly correlated with higher rates of nonorgan confined disease and with cancer-specific and overall mortality. ${ }^{7-11}$ These findings cannot be generalized to patients with bladder cancer treated with PC because this constitutes a select category of patients with a favourable disease profile and presumably better prognostic potential. To date, no study has investigated the impact of delaying PC on disease outcome.

Median PC treatment delays in Quebec have more than doubled over the past 13 years. Median and mean delays in this study were 4 and 8 weeks, respectively. The reported median delays between

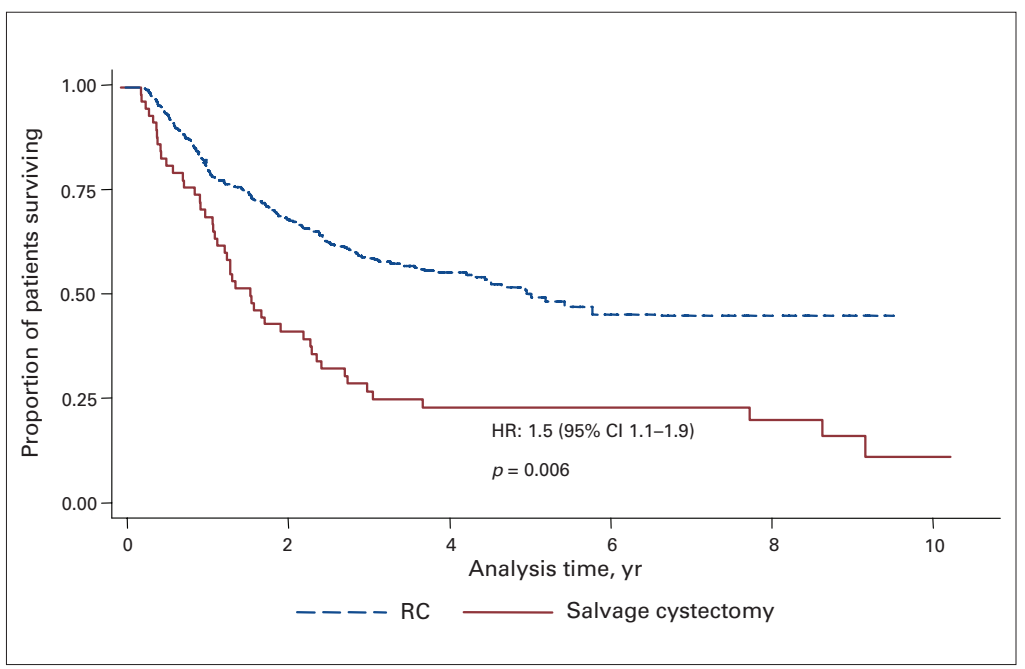

Fig. 3. Overall survival of patients who underwent salvage radical cystectomy $(\mathrm{RC})$ after an initial partial cystectomy compared with those who underwent upfront $\mathrm{RC}$ for invasive bladder cancer. $\mathrm{Cl}=$ confidence interval; $\mathrm{HR}=$ hazard ratio.
TURBT and RC ranged from 4.7 to 13.7 weeks, ${ }^{9,14}$ whereas the mean delays ranged from 7.9 to 66.0 weeks. ${ }^{11,15}$ The published 90-day cutoff period for delay was first reported by Hara and colleagues. ${ }^{16}$ This chosen cutoff point was explained by Sanchez-Ortiz and colleagues, ${ }^{11}$ who, owing to their small number of patients, chose to combine patient delays with similar HRs into 2 groups: delays of 12 weeks or less and delays of more than 12 weeks. In our study, patients delayed more than 12 weeks were at significantly increased risk of requiring a salvage $\mathrm{RC}$. This risk steadily increased with longer delays. However, PC treatment delays were not associated with overall survival. This was not entirely unexpected, since patients who are good candidates for PC are those with more favourable tumour profiles. In such cases, the earliest consequence of a treatment delay would be local failure with the need for more radical surgery $(\mathrm{RC})$. Patients treated early with $\mathrm{PC}$ have a decreased probability of requiring salvage $\mathrm{RC}$, a procedure with relatively higher surgical morbidity. ${ }^{17}$ Interestingly, patients who underwent salvage $R C$ had worse survival than patients who had upfront RC for invasive bladder cancer.

Apart from the retrospective nature of our analysis, other limitations of the study include the fact that it was based on provincial billing codes that lack important information such as preoperative comorbidities, disease stage and quality of the pelvic lymphadenectomy. A potential selection bias may exist because some physicians might elect to perform PCs in high-risk patients. As such, this might bias the survival results of patients who underwent salvage RC compared with those who had upfront RC. One of the major strengths of our study was the sample size, which was the largest reported in the literature on PC.

\section{Conclusion}

Treatment delay in patients with bladder cancer managed with PC was associated with higher risk of salvage RC. Patients with bladder cancer who underwent salvage RC had worse outcomes than those who underwent upfront cystectomy.

From the Department of Surgery (Urology), McGill University, Montréal, Que.

This article has been peer reviewed.

Competing interests: Supported by the Fonds de la Recherche en Santé du Quebec. 


\section{References}

1. American Cancer Society. Cancer facts and figures 2007. Atlanta: The Society; 2007.

2. Raghavan D, Quinn D, Skinner DG, et al. Surgery and adjunctive chemotherapy for invasive bladder cancer. Surg Oncol 2002;11:55-63.

3. Holzbeierlein JM, Lopez-Corona E, Bochner BH, et al. Partial cystectomy: a contemporary review of the Memorial Sloan-Kettering Cancer Center experience and recommendations for patient selection. J Urol 2004;172:878-81.

4. Kassouf W, Swanson D, Kamat AM, et al. Partial cystectomy for muscle invasive urothelial carcinoma of the bladder: a contemporary review of the M. D. Anderson Cancer Center experience. J Urol 2006;175:2058-62.

5. Dandekar NP, Tongaonkar HB, Dalal AV, et al. Partial cystectomy for invasive bladder cancer. J Surg Oncol 1995;60:24-9.

6. Inove K, Slaton JW, Perrotte P, et al. Paclitaxel enhances the effects of the antiepidermal growth factor receptor monoclonal antibody ImClone C225 in mice with metastatic human bladder transitional cell carcinoma. Clin Cancer Res 2000;6:4874-84.

7. Chang SS, Hassan JM, Cookson MS, et al. Delaying radical cystectomy for muscle invasive bladder cancer results in worse pathological stage. J Urol 2003;170:1085-7.

8. Komuta K, Okudaira $S$, Haraguchi $M$, et al. Identification of extracapsular invasion of the metastatic lymph nodes as a useful prognostic sign in patients with resectable colorectal cancer. Dis Colon Rectum 2001;44:1838-44.

9. Mahmud SM, Fong B, Fahmy N, et al. Effect of preoperative delay on survival in patients with bladder cancer undergoing cystectomy in Quebec: a population based study. J Urol 2006; 175:78-83.
10. May M, Nitzke T, Helke C, et al. Significance of the time period between diagnosis of muscle invasion and radical cystectomy with regard to the prognosis of transitional cell carcinoma of the urothelium in the bladder. Scand I Urol Nephrol 2004;38:231-5.

11. Sanchez-Ortiz RF, Huang WC, Mick R, et al. An interval longer than 12 weeks between the diagnosis of muscle invasion and cystectomy is associated with worse outcome in bladder carcinoma. J Urol 2003; 169:110-5.

12. Zelder M. Spend more, wait less? The myth of underfunded medicare in Canada. Vancouver: The Fraser Institute; 2000.

13. Esmail N, Walker M. Waiting your furn: hospital waiting lists in Canada. 12th ed. Vancouver: The Fraser Institute; 2004.

14. Chahal R, Sundaram SK, Iddenden R, et al. A study of the morbidity, mortality and longterm survival following radical cystectomy and radical radiotherapy in the treatment of invasive bladder cancer in Yorkshire. Eur Urol 2003;43:246-57.

15. Volkmer BG, Kuefer R, Bartsch $G \mathrm{Jr}$, et al. Effect of a pTO cystectomy specimen without neoadjuvant therapy on survival. Cancer 2005;104:2384-91.

16. Hara I, Miyake H, Hara S, et al. Optimal timing of radical cystectomy for patients with invasive transitional cell carcinoma of the bladder. Jpn J Clin Oncol 2002;32:14-8.

17. Laufer $M$. Transurethral resection and partial cystectomy for invasive bladder cancer. Semin Urol Oncol 2000;18:296-9.

Correspondence: Dr. Wassim Kassouf, Division of Urology, McGill University Health Center, 1650 Cedar Ave., Rm. L8-315, Montréal QC H3G 1A4; fax 514 934-8297; wassim.kassou@muhc.mcgill.ca

\section{Change of address}

We require 6 to 8 weeks' notice to ensure uninterrupted service. Please send your current mailing label, new address and the effective date of change to:

\section{CUAJ}

1155 University Ave., Suite 1303

Montréal QC H3B 3A7

fax $514395-1664$ 